between two forts situated on rocky elevations - St. Julian and Santa Cruz. It is very narrow, scarcely a mile in width, though within the entrance the bay expands, and it runs a considerable distance inland, and is broken into numerous smaller bays with intervening promontories, and studded with numerous rocky islands. On the left side of the entrance are situated the Sugar-loaf and the Corcovado mountains, respectively attaining heights of 1270 feet and 2272 feet. More towards the sea is the Gavia, a very curiously-shaped hill, 2575 feet high, and further inland are the peaks of Tijuca, the highest attaining a height of 3316 feet. On the right hand side of the bay are situated the Organ mountains, picturesque peaks of still greater elevation.

The city of Rio is situated on a peninsula jutting out into the bay on the south-western side, and not far from the entrance. The site is low and level, and does not afford any natural facilities for drainage, and the attempts which have been made to improve it do not appear to have been very successful. The outlet of the drains is into a small bay within the larger one, through which there can be very little current, instead of being carried into the open sea. The entrance to the bay is too narrow to admit of a free sweep of tide, and the mountains which surround the town, though they add greatly to the beauty of the site, must interfere with the free perflation of air. The supply of water is also at present very defective. The streets are narrow and the houses built very closely together, and closed at the back. I have also reason to believe that very many of them lack the proper arrangements for cleanliness and comfort. It is therefore no cause for surprise that the town is very unhealthy, and that yellow fever prevails, more or less, during the hot season every year. Arrangements are being carried out for an increased supply of cood water to the town, and it is to be hoped that this will lead to an improvement in its sanitary condition. Though, however, Rio itself is so unhealthy, there are at short distances from the city localities that are in every respect unexceptionable. The Europeans generally reside during the unhealthy season at hotels or country houses on the hills a few miles out of town; and of these Tjjuca, about eight miles from Rio and 800 feet above the sea, is one of the most popular places of residence. I myself lived while there at Anderye Grande, at an hotel on the side of a mountain about four miles from Rio, and 400 feet above the bay. Here the mornings and evenings were delightfully cool, and the hotel commanded a beautiful view down a forest-clad valley, with Rio and the Organ mountains in the distance; and I have every reason to believe that the place was quite healthy.

From the peculiar form of the mountains around Rio, the impression would be conveyed that they owe their origin to volcanic action, but this is not the case. They consist of primitive rocks-quartz, granite, gneiss, sienite, \&c. It is the opinion of Agassiz that the country has been subjected to the action of glaciers, and this opinion he founds upon the existence of travelled boulders in situations which they conld scarcely occupy unless conveyed thither by ice.

I should have wished to obtain some information in reference to the climate of Rio and Brazil, but in this I have very imperfectly succeeded. From the great extent of the country, which ranged from $4^{\circ}$ of North latitude to $33^{\circ} 40^{\prime}$ South latitude, a distance of about 2600 miles, it will readily be understood that the temperature must vary greatly in different parts. At Para, in the north, it has a mean of $81^{\circ} \mathrm{F}$, and a range of from $76^{\circ}$ at night to $85^{\circ}$ in the day; at Ceara the range is from $83^{\circ}$ to $75^{\circ}$; at Pernambuco from $77^{\circ}$ to $86^{\circ}$; and at Bahia from $75^{\circ}$ to $85^{\circ}$. The temperature of Rio is somewhat less, while at Rio Grande do Sul, in the south, it is $44^{\circ}$ in the winter and $85^{\circ}$ in the summer. At the River Plate the temperature is said to have an average of $65^{\circ}$. Of the rainfall $I$ am unable to give any specific statement, but from the number of running streams and the extreme luxuriance of the vegetation, it is evident that there must be a large fall of rain.

$$
\text { (To be concluded.) }
$$

ON the 16th ult., a large number of the inhabitants of Ottery St. Mary and its vicinity, assembled in the Town Hall for the purpose of asking Dr. Whitby to accept a proof of the estimation in which he is held by those among whom he has practised for nearly twenty-eight years. The testimonial consisted of a gold watch, value $£ 25$, and a purse of 150 guineas.
A THIRD SERIES OF CASES OF

STONE IN THE BLADDER TREATED BY LITHOTRITY AND RAPID EVACUATION OF THE FRAGMENTS (BIGELOW'S METHOD).

BY WALTER J. COULSON, F.R.C.S.EF.

CASE 1.-Edward $\mathrm{S}-$, aged fifty-nine, living in York shire, came under observation Feb. 16th, 1880. He complained of the ordinary symptoms of stone in the bladder, and had suffered from them for about three years; had only once noticed a little blood in the urine. Not subject to gout or rheumatism ; no family history of stone; has not suffered from pain in the back or loins. Frequency of micturition is now the most prominent symptom; he passes urine nearly every quarter of an hour during the day. The secretion is of a pale-sherry colour, has an alkaline reaction, sp. gr. 1018, and deposits mucus and phosphates. The patient's general health is good. A small calculus is readily detected on sounding.

On Feb. 19th, the patient being under the influence of ether, and the narrow meatus urethra having been incised with a bistourie cachée, I crushed the stone about twenty times, using the fenestrated lithotrite. Bigelow's apparatus with the curved evacuating tube was then applied, and the detritus removed. Owing to the rigidity of the enlarged prostate, some little difficulty was experienced in the introduction of the tube. In order to overcome this, I had recourse to a method which I can confidently recommend for adoption in all similar cases. Having passed the tube down the urethra as far as it would go, I attached the bottle and gently injected a little water. The fluid, finding its way into the bladder, dilated the urethra, and the tube readily followed. On completion of the operation, the bladder was examined with the non-fenestrated instrument and no fragments were detected. The operation lasted twenty-four minutes, and was well borne by the patient. The weight of the fragments removed was seventy grains.

Two hours after the operation the patient passed urine freely; there was no trace of blood, and only slight pain in the urethra. At 10.15 P.M., temperature $99^{\circ}$, pulse 72 , the patient comfortable in every way. On the following day the condition was perfectly satisfactory; no pain, no débris in urine, which was passed freely. The patient was allowed to sit up on the 2lst, and on the 23rd (the fourth day after the operation) he was free from all symptoms of calculus.

CASE 2.-Joseph L-, aged seventy-one, came under observation March 2nd, 1880, suffering intensely from symptoms of disease of the urinary organs. He stated that more than twenty-five years ago he began to notice brick-red sediment in his urine, and occasionally larger fragments. There was at first not much local irritation, but a few years later micturition became very frequent, and he suffered from pain at the end of the penis, and smarting along the urethra. About sixteen years ago he appears to have had an attack of acute cystitis, which was at the time attributed to "catching cold." The symptoms were very severe, and the urine subsequently became very offensive, and often contained a great deal of blood. The intensity of the symptoms afterwards abated, but about four months ago they again became very severe. When first seen the patient was passing urine every half hour, and suffering intense pain, which was greatly aggravated by jolting. The urine was very offensive, strongly ammoniacal, with a copious white gelatinous precipitate consisting of pus cells, phosphates, and much vesical epithelium; sp. gr, 1012. The patient had a careworn look indicative of severe suffering, and had lost flesh rapidly during the last few months. No history of gout or rheumatism, and no apparent hereditary tendency to those affections or to calculus ; the patient had always lived freely. A large calculus detected on examination.

On March 4th, ether having been administered, I crushed the stone nearly fifty times, using a fenestrated lithotrite. The parts were much relaxed, and on that account there was some difficulty in introducing the instrument. After using the curved tube and thoroughly washing out the bladder, the lithotrite was reintroduced and the fragments repeatedly 
crushed. The tube was again used and a quantity of débris removed, but there were still many fragments left in the bladder. The patient was under the influence of ether for forty-seven minutes, and upon the whole bore the operation well, but owing to his condition it was not thought expedient to prolong the sitting. The weight of the fragments removed was 210 grains. After the operation a warm poultice was applied to the supra-pubic region. On the evening of the day, temperature 102 $2^{\circ}$ pulse 100 . Some pain in passing water; urine clear, without offensive odour; no detritus.

On the following day the patient was comparatively comfortable; had had a good night, and there had been no rigor. The pain in passing urine was somewhat less, and the calls to do so less frequent. Ordered a suppository containing half a grain of morphia. In the evening a quantity of grit was passed. Forty-five ounces of urine were voided during the twenty-four hours succeeding the operation. On the second and third days the condition of the patient was satisfactory. The urine was abundant and free from offensive odour, and contained several fragments. On the fourth day after the sitting the urine again became offensive, and the muco-purulent deposit increased in quantity.

On the loth of March the operation was repeated, the patient being, as before, under ether. I made eleven distinct crushings, after having with some difficulty secured what from its size appeared to be a second calculus. The operation lasted about half an hour. In consequence of the patient's weak condition it was not thought advisable to persevere with the operation, during which, however, sixty-five grains of débris were removed. In the evening the patient's condition was comparatively satisfactory; there were no rigors, and the urine was free from blood. Pulse 100, temperature $103^{\circ}$. Some pain above pubes and in passing urine. The morphia suppository was repeated. On the following day the pulse and temperature were normal. Forty-five ounces of urine were passed in the twenty-four hours succeeding the operation. During the next three days the patient's condition still further improved. The urine, however, contained a great quantity of pus and vesical epithelium, and had a slightly ammoniacal odour.

On March 15 th the patient was submitted to a third operation. The fenestrated lithotrite was first used, and was followed by Bigelow's apparatus. The non-fenestrated lithotrite was subsequently introduced, and several small fragments were crushed in succession. The bladder was then washed out as before, and débris weighing sixty grains was removed. The operation lasted thirty-five minutes. The patient, however, appeared much weaker than previously, and it was deemed unsafe to prolong the administration of ether. In the evening the patient expressed himself as feeling more comfortable. Temperature $100^{\circ}$; pulse 96 tongue moist ; no thirst.

On the following day the temperature and pulse were normal; urine free from blood, but containing mucopurulent matter. No débris passed. On the second day after this sitting the patient's condition appeared to be so far improved that he was allowed to take a short drive. On March 18 th he was reported to be still better, the urine was clearer, and the pain less troublesome. Ordered a mixture consisting of the decoctions of uva ursi and triticum repens. The improvement continued until the 21 st of the month when he began to complain of great pain in the bowels and in passing urine, and of thirst and loss of appetite. The tongue became dry, and the abdomen tympanitic. On the following day all the symptoms were aggravated, the meteorism increased, vomiting and hiccough took place, and the urine dribbled away involuntarily. The patient died at 2 A.M. on March $23 \mathrm{rd}$.

Post-mortem examination sixty-three hours after death.Body fairly nourished; signs of decomposition evident. Heart and lungs bealthy. In abdomen evidences both of recent and old-standing peritonitis. Bladder adherent to neighbouring organs, its walls thickened and pulpy, breaking down on slight pressure; all its coats in an advanced stage of degeneration; its cavity filled with pus; a single tiny calculus, of the size and shape of a pea, was found imbedded in the pulpy mucous membrane of the posterior wall. No fragments discoverable. Ureters much dilated, and filled with pus. Numerous abscesses in both kidneys.

CASE 3. - Martin O-, aged fifty-four, came under observation April 6th, 1850, complaining of the ordinary symptoms of calculus in the bladder. He stated that during the last five years he had passed several small calculi, and that for some time before these began to appear his urine was often high-coloured, and deposited a pinkish sediment and particles of gravel. During the last nine months the pain and frequency of micturition had become much more troublesome, and his urine had several times contained blood. The pain apparently was not increased by movement; it was most marked at the end of the penis. The patient had always lived freely. There was no family history of gout or rheumatism. His urine, when examined was found to be of a light sherry colour, with an acid reaction and a deposit of urates, uric acid, and vesical epithelium; sp. gr. 1015. A calculus detected on sounding.

On April 7th, the patient being under the influence of ether, I passed a fenestrated lithotrite, and found that the bladder contained several calculi. These were crushed eighteen times in succession, and Bigelow's straight tube subsequently introduced. This, however, became blocked up by a collection of fragments, and had to be removed, and the washing out was completed with the aid of a curved tube. On withdrawal, the bladder was examined with a non-fenestrated lithotrite and a sound in succession, but no fragment could be detected. The operation lasted thirty minutes, and was well borne by the patient. The weight of the fragments removed was one hundred grains.

The operation afforded complete relief to all the symptoms, and was not followed by any local or constitutional dis: turbance. The urine showed no traces of calculus, and on the third day after the operation the patient expressed himself as freed from all his previous symptoms.

Remarlss. - The second of these cases presents, in all its features, a marked contrast to the other two. The duration of the symptoms, their severity, and the obviously profound constitutional disturbance conspired to render the patient a very unpromising subject for any operative procedure. The first and second sittings were, however, followed by far less local and constitutional irritation than might have been expected; and had the patient been able to sustain a more prolonged administration of the anæsthetic, it is probable that the bladder would have been freed from all fragments at the second sitting. The third operation was not immediately followed by any symptoms indicative of the approaching fatal termination. These did not appear until the sixth day, the patient's condition in the interval being so far satisfactory that he was allowed to take a short drive. The state of the urinary organs, as revealed by the autopsy, clearly demonstrated the impossibility of a successful result, and that temporary relief of the patient's sufferings was all that could have been attained. For many years the symptoms had been indicative of the presence of a calculus in the bladder, and the marked pathological changes were exactly those usually found in cases of long standing where proper surgical aid has not been afforded. With regard to the operation in this case, the difficulty in passing the tube, due to the extremely flaccid condition of the urethra, is a point worthy of notice. Instead of gliding over the surface, the tube was felt to be continuously resisted in its passage by a fold of the lining membrane and wall of the urethra. In the first case, the difficulty in introducing the tube was due to the enlargement of the prostate and consequent rigidity of the prostatic portion of the urethra. It is most important in all such cases to avoid using force. I have reason to believe that in one if not two recent instances a fatal result has followed unsuccessful attempts to introduce the full-sized evacuating-tube. It is obvious that if by a protracted operation we thoroughly break up a calculus and then fail to relieve the bladder of the numerous sharp fragments we have made, we expose the patient to serious risk, and his prospects will in all probability be further impaired by repeated but unsuccessful attempts at introducing the evacuating-tube. The plan of injecting a little fluid, as described in the notes of the first case, will be found to answer equally well, whether the difficulty be due to the abovementioned causes, or to another sometimes met with-viz., the adhesion to the urethral mucous membrane of pulverulent débris. Obstruction from this cause was experienced in one of the cases recorded in THE LANCET, Jan. 31st, of this year. While taking care not to injure the urethra by the introduction of the tube, it is, of course, equally necessary to avoid pinching and lacerating the mucous membrane of the bladder when using the lithotrite. This accident is likely to occur if the lithotrite be pressed against the base of the bladder so as to produce a hollow into which the stone may fall, and it may be guarded against by adopting Civiale's method, in which contact with the resical walls is as far as 
possible avoided. In none of my cases was there auy trace of blood in the urine passed after the operation. The results in the first and third cases of the series now reported must be regarded as eminently satisfactory, and well illustrate the advantages of Bigelow's method. No local or general disturbance was set up by the operation, while the relief afforded was immediate and complete.

Harley-street, W.

\section{ON GLYCERINE IN FLATULENCE, ACIDITY, AND PYROSIS.}

\section{BY SYDNEY RINGER, M.D., $A X D$ WILLIAM MURRELL, M.D.}

AN old gentleman, who for many years suffered from distressing acidity, read in a daily paper that glycerine added to milk prevents its turning sour, and he reasoned thus: "If glycerine prevents milk turuing sour, why should it not prevent we turning sour?" and he resolved to try the efficacy of glycerine for his acidity. The success of his experiment was complete, and whenever tormented by his old malady he cures himself by a recourse to glycerine. Indeed, he can now take articles of food from which he was pre viously compelled to abstain, provided always that he takes a drachm of glyceriue immediately lefore, with, or directly after, his food. He recommended this treatment to many of his friends - sufferers like himself - and one of these mentioned the above circumstances to us.

We have since largely employed glycerine, and find it not only very useful in acidity, butalso in flatulence and pyrosis, and that it sometimes relieves pain. We meet with cases where flatulence, or acidity, or pyrosis is the only symptom but more frequently these symptoms are combined. Some patients rift up huge quantities of wind without any other symptoms than depression of spirits; in others we get flatulence and acidity, one or other predominating; and we meet with others who suffer from acidity, flatulence, and also pyrosis. In all these various forms we find glycerine useful, and in the great majority of cases very useful. We do not mean to say that in all cases it is superior to other remedies for these complaints; indeed, in several instances it has only partially succeeded, where other remedies at once cured. On the other hand, in some cases glycerine speedily and completely succeeded, where the commonly used remedies for acidity and flatulence completely failed. We do not pretend to estimate its relative value to other remedies; we are only anxious to draw attention to its virtues.

Gas is in some instances formed in the stomach, in others in the large intestine, in sorae patients in both. Our observations were made on stomach flatulence, and as olycerine is so readily absorbed we should hardly expect that it would influence the formation of wind in the colon, except given in large doses, and when it acts as a slight laxative, and so expels the putrefying mass which forms the wind.

In some cases it removes pain and vomiting, probably, like charcoal, by preventing the formation of acrid acids, which irritate delicate and irritable stomachs.

We suggest that it acts by retarding or preventing some forms of termentation and of putrefaction. J. Mekulics ${ }^{1}$ shows that glycerine prevents putrefaction of nitrogenous substances, as of blood diluted with water, which speedily decomposes at the ordinary temperature of the air. Two per cent. of glycerine retarded decomposition for twentyfour hours; 10 per cent. for five days. If the fluid were placed in the hatching oven, then 2 per cent. retarded decomposition for several hours, 10 per cent. for forty-eight hours, and 20 per cent. altogether prevented putrefaction. He also proves that glycerine destroys bacteria and prevents the formation of septic poison, though it will dissolve and preserve the septic poison itself.

Dr. E. Murk ${ }^{2}$ fiuds that 2 to 3 per cent. will delay lactic fermentation in milk from eighteen to twenty-four hours.

Burnbam Wilmot, 1860, says glycerine preserves meat so that after several months' immersion the meat is sweet and can be eaten ; and Demarquay proves that both animal and vegetable substances may be kept for six wceks to two months by glycerine.

Glycerine, however, does not prevent the digestive action of pepsin and hydrochloric acid; hence, whilst it prevents the formation of wind and acidity, probably by checking fermentation, it in no way hinders digestion. We administer a drachm to two drachms either before, with, or immediately after food. It may be given in water, coffee, tea, or lemon and soda water. In tea and coffee it may replace sugar, a substance which greatly favours flatulence, as, indeed, does. tea in many cases. In some instances a cure does not occur till the lapse of ten days or a fortnight.

\section{A CASE OF IITHO-NEPHROTOMY.}

BY E. HOOPER MAY, F.R.C.S., SURGEON TO THE TRAINING MOSPITAI, TOTTENHAM.

Mrs. B—, aged fifty-five, a pale but fairly healthylooking woman, complained, in July, 1879, that her urine was thick and very offensive, and that for some time past, though able to perform her duties, she had not been feeling well. The urine was found to contain pus. Upon examination on the 17th September, a large tumour was found on the right side of the abdomen, occupying the space between the last rib and the crest of the ilium, and bulging anteriorly and into the loin. This was believed to be a suppurating kidney, and the opinion received confirmation from the fact that although at the time of the examination the patient had been passing clear healthy urine, almost immediately after the manipulation she passed a quantity which was thick and offensive. On the 15th October the patient was admitted into the Tottenham Training Hospital. During the preceding three weeks there had been more or less pyrexia. The tumour had increased in size, and the urine, which had varied, was clear. When thick, it had been found to contain a large quantity of muco-pus and many bloodcells, but no caste. The history of the case was briefly as follows:-Thirteen years ago the patient had a sudden attack of vomiting, and pain in the right side, which lasted for a week. A lump, about the size of an egg, was found by the doctor, examination of which caused great pain, followed within a day by its disappearance, nothing abnormal being noticed about the urine. A bout a year later she had a similar attack, the pain lasting eight weeks. At this time she was seized with a straining sensation, and passed a large quantity of thick urine, after which the lump disappeared; and until recently she has continued free from all urinary troubles.

Dec. 4th. - Since last note the patient has continued much the same. The urine has varied in quantity from twenty to forty-nine ounces in the twenty-four hours, it has been acid and free from albumen, and has been occasionally thick and offensive. The escape of pus with the urine has always been followed by a sense of relief to the patient. She has felt able to sit up easily in bed, whilst before the size of the tumour had impeded such movements.

In consultation with my colleague, Dr. Lichtenberg, it was determined to open the cyst through the abdominal wall, after inducing adhesion by the method advocated by the late Dr. Simon of Heidelberg. The most prominent part of the tumour having been selected, two long silver exploring trocars were introduced in a line with the anterior border of the axilla, at the distance of five centimetres from each other, and two others in a transverse direction midway between the two first, and two centimetres apart

Offensive pus flowed from each cannula. A small quantity was thus allowed to escape, and afterwards the cannulas were stopped and carefully fastened in

11th. - The patient had continued much as before the introduction of the trocars. The tumour was slightly reduced in size, and upon it a circular area, of which a line drawn from one vertically-placed needle to the other formed the diameter, was prominent. In this line, from needle to needle, an incision was carried through the abdominal wall and into the cyst; a considerable quantity of offensive pus escaped, and, on introducing a director, a stone was at once felt. This was grasped by a lithotomy forceps with some 